\title{
IN THIS ISSUE:
}

Takeo Oku

Direct structure analysis of advanced nanomaterials by high-

DOI 10.1515/ntrev-2012-0018

Nanotechnol Rev 1 (2012):

389-425 resolution electron microscopy
Review: HREM image of $\mathrm{TlBa}_{2} \mathrm{Ca}_{3} \mathrm{Cu}_{4} \mathrm{O}_{11}$ taken with the incident beam parallel to the a-axis together with a structure model after image processing.

Keywords: atomic structure; boride; boron nitride; high-resolution electron microscopy; inorganic materials; nanostructured materials; oxide.
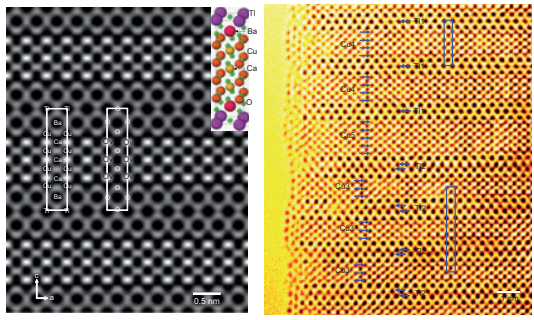

Aldo S. Gago, Aurelien Habrioux and

Nicolas Alonso-Vante Tailoring nanostructured catalysts conversion systems

DOI 10.1515/ntrev-2012-0013

Nanotechnol Rev 1 (2012):

427-453 for electrochemical energy
Review: Novel materials and supports such as graphene are being widely studied; this review mainly explores the synthesis, the surface electrochemical reactions and the use of nanoparticles to convert efficiently chemical energy into electricity.

Keywords: $\mu \mathrm{DMFC}$; electrochemistry; LFFC; Li-air battery; nanoparticles;

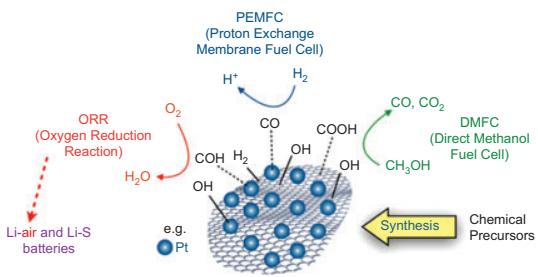

Tailoring Nanoparticles and Supports nucleation; PEMFC; synthesis. 